\title{
Referrals to a regional allergy clinic - an eleven year audit
}

Ray B Jones ${ }^{1 *}$, Paul Hewson ${ }^{2}$, Edward R Kaminski ${ }^{3}$

\begin{abstract}
Background: Allergy is a serious and apparently increasing public health problem yet relatively little is known about the types of allergy seen in routine tertiary practice, including their spatial distribution, co-occurrence or referral patterns. This study reviewed referrals over an eleven year period to a regional allergy clinic that had a well defined geographical boundary. For those patients confirmed as having an allergy we explored: (i) differences over time and by demographics, (ii) types of allergy, (iii) co-occurrence, and (iv) spatial distributions.
\end{abstract}

Methods: Data were extracted from consultant letters to GPs, from September 1998 to September 2009, for patients confirmed as having an allergy. Other data included referral statistics and population data by postcode. Simple descriptive analysis was used to describe types of allergy. We calculated 11 year standardised morbidity ratios for postcode districts and checked for spatial clustering. We present maps showing 11 year rates by postcode, and 'difference' maps which try to separate referral effect from possible environmental effect.

Results: Of 5778 referrals, 961 patients were diagnosed with an allergy. These were referred by a total of 672 different GPs. There were marked differences in referral patterns between GP practices and also individual GPs. The mean age of patients was 35 and there were considerably more females (65\%) than males. Airborne allergies were the most frequent (623), and there were very high rates of co-occurrence of pollen, house dust mite, and animal hair allergies. Less than half (410) patients had a food allergy, with nuts, fruit, and seafood being the most common allergens. Fifteen percent (142) had both a food and a non-food allergy. Certain food allergies were more likely to co-occur, for example, patients allergic to dairy products were more likely to be allergic to egg. There were age differences by types of allergy; people referred with food allergies were on average 5 years younger than those with other allergies, and those allergic to nuts were much younger (26 Vs 38) than those with other food allergies.

There was clear evidence for spatial clustering with marked clustering around the referral hospital. However, the geographical distribution varied between allergies; airborne (particularly pollen allergies) clustered in North Dartmoor and Exmoor, food allergies (particularly nut allergies) in the South Hams, and on small numbers, some indication of seafood allergy in the far south west of Cornwall and in the Padstow area.

Conclusions: This study shows marked geographical differences in allergy referrals which are likely to reflect a combination of environmental factors and GP referral patterns. The data suggest that GPs may benefit from education and ongoing decision support and be supported by public education on the nature of allergy. It suggests further research into what happens to patients with allergy where there has been low use of tertiary services and further research into cross-reactivity and co-occurrence, and spatial distribution of allergy.

\footnotetext{
* Correspondence: Ray.Jones@plymouth.ac.uk

${ }^{1}$ Faculty of Health, University of Plymouth, 3 Portland Villas, Plymouth PL4 8AA, UK

Full list of author information is available at the end of the article
}

\section{Biomed Central}

(C) 2010 Jones et al; licensee BioMed Central Ltd. This is an Open Access article distributed under the terms of the Creative Commons Attribution License (http://creativecommons.org/licenses/by/2.0), which permits unrestricted use, distribution, and reproduction in any medium, provided the original work is properly cited. 


\section{Background}

The predominant allergies seen in allergy practices are type I hypersensitivity (IgE mediated) reactions. These occur rapidly, with typical symptoms (urticaria, angioedema, conjunctivitis, rhinitis, wheezing or anaphylaxis), have a well-defined mechanism and have validated tests to confirm the diagnosis. Non toxic adverse reaction to food can be a result of food allergy or food intolerance [1]. Food allergies can be either IgE mediated (as above) or non-IgE mediated (usually with delayed onset, gastrointestinal or non-specific symptoms, where the mechanism is unclear and are harder to diagnose with no validated tests). Lack [1] reported that IgE-mediated food allergies affect between 6 and $8 \%$ of children in the United Kingdom and the United States. Although up to $25 \%$ of adults report symptoms that may be related to certain foods, the prevalence of food allergies among adults is less than 3\%. Nevertheless, admissions in English NHS hospitals for (all cause) anaphylaxis (severe allergic reactions) rose steadily from 2821 in 2004-05 to 3595 in 2008-09 [2]. Anaphylaxis is responsible for the death of approximately 1 to 3 individuals per million population [3].

In 2006 the Department of Health published a review of Allergy Services [4]. They recommended action to improve services and pointed to the need to: (i) establish levels of need for services for allergy, (ii) explore the scope for creating additional training places for allergists, (iii) consider the development of guidance for referral and care pathways. In 2010, a joint Royal College of Physicians and Royal College of Pathologists Working Party surveyed respiratory physicians, immunologists, allergists, and others and made recommendations about the organisation of allergy services [5]. However, relatively little has been published on the effectiveness and efficiency of the referral process to tertiary centres.

Studies from a number of European countries have shown evidence of geographical differences in allergy prevalence [6-16]. Meta-analyses have confirmed a marked heterogeneity in the prevalence of food allergy that could be a result of real differences between populations or differences in study design or methodology $[17,18]$.

The Peninsula Allergy Service (PAS) was set up in 1996 at Derriford Hospital, Plymouth, serving Devon and Cornwall in the UK. Initially, patients of all ages (including children) were seen, but from 2004, children were normally referred to a paediatric clinic. The SW Peninsula of Devon and Cornwall is a largely rural area with population (2001) of 1.6 million. Travel from the far south west to Plymouth can be time consuming and expensive (Land's End to Plymouth is a 2-3 hour 115-mile trip each way by car). The shape of this region, bounded by the sea, means that referral to any other tertiary allergy service is extremely unlikely; our audit of referrals was therefore for a geographically defined population.

The aim of this study was to audit eleven years of patients referred to the PAS. Amongst those diagnosed as having an allergy, we aimed to explore: (i) differences over time and by demographics, (ii) the types of allergy, (iii) co-occurrence, and (iv) spatial distributions to identify areas with high or low referral of true cases.

\section{Methods}

\section{Ethics}

Ethic approval was not required as this was purely an audit project using anonymised patient data

\section{Data Sources}

The main source of data was consultant letters to GPs summarising the diagnosis of patients, archived from September 1998 to September 2009. These letters were for patients who, following the taking of a detailed history, were confirmed as having an allergy (type I hypersensitivity) on the basis of a 'positive' skin prick test or specific IgE test in the clinic. A skin prick test was considered positive when the diameter of the wheal exceeded the diameter of the negative control by $3 \mathrm{~mm}$ and when a flare reaction was also present. A specific IgE test was considered positive when the value exceeded $0.7 \mathrm{kUA} / \mathrm{l}$. We did not include borderline positive results as positive. Letters were reviewed, extracting the clinic date, doctor seen, patient's name, gender, date of birth, postcode, GP, and diagnoses. There were 1076 visits (letters to GPs). Ninety patients had more than one consultation; we deleted 111 subsequent consultations just keeping the earliest consultation for 965 individuals. Four patients had postcodes that were out of area (from armed forces, Somerset, and Bristol). Further analysis was on anonymised data for 961 patients.

Supplementary sources of data were: (1) New referral statistics to the Peninsula Allergy Service extracted from the hospital information system (used to assess the proportion of referrals who were diagnosed as having an allergy); (2) Population data by postcode, aggregated from 2001 census data from the Office of National Statistics, used as the denominator to calculate rates by postcode area; (3) Deprivation decile data by postcode for England, from Dr Iain Paterson, University of Glasgow, used in one cross-tabulation to see if the referred and diagnosed patients were equally likely to be from different deprivation deciles.

\section{Aggregation and 'cleaning' of allergy diagnoses}

The original allergy diagnoses were kept as part of the database but diagnoses were recoded and aggregated 
based on common characteristics of the allergen such as method of entry to the body (e.g. airborne Vs food), source (e.g. the sea), and common English usage on categories (e.g. nuts).

\section{Non spatial analysis}

We used simple descriptive analyses to describe types of allergy and differences over time, by age at referral, distributions by GP and practice location. For example, we investigated co-occurrence of (non-aggregated) food allergies by 21 cross-tabulations and Fisher exact test highlighting those where a Fisher exact test gave $\mathrm{p}<$ 0.024, that is applying a Bonferroni correction to set a level where co-occurrence may be more than expected by chance. More details of analysis are presented in Additional File 1.

\section{Spatial analysis}

There may be a number of underlying reasons why there are differences in the spatial distribution of allergies referred to, and diagnosed at, a regional allergy service, including: (1) unmet need, i.e. people with allergies who may not have been diagnosed, (2) alternative referral or treatment, i.e. patients who are either diagnosed and treated by the GP or referred to another hospital clinic, (3) 'real' spatial differences perhaps due to environmental influences. To explore this we used postcodes for each patients (numerator), postcode district boundary data from Edina http://edina.ac.uk/digimap/index.shtml, and denominator populations from the 2001 Census. There were 109 postcode districts in the four postcode areas of TQ (Torquay), EX (Exeter), PL (Plymouth), TR (Truro) covering Devon and Cornwall. We calculated the 11 year standardised morbidity ratio for allergy referrals in each postcode district by comparing the observed count of referrals with the expected count using simple internal standardisation based on total numbers of referrals for the Peninsula and total population count in each district. It is standard to assume that the observed counts follow a Poisson distribution. We used three methods to determine whether this assumption was consistent with the data: (i) a $\chi^{2}$ test for overdispersion, (ii) Potthof-Whittinghill's test of overdispersion [19], and (iii) Moran's I test of spatial autocorrelation [20]. We present three maps: (i) 'crude' 11 year rates (number of cases/postcode population), (ii) 'smoothed' maps which try to allow for the small numbers in each postcode district by averaging uncertainty across neighbouring districts, and (iii) 'difference' maps which try to remove the 'referral effect' that might be due partly to distance from Derriford Hospital and GP propensity to refer, leaving any possible environmental effect. More details of the statistical analysis used in the spatial analysis and mapping are given in Additional File 2.

\section{Results}

\section{Allergy cases as a proportion of all referrals}

Table 1 presents data from 'counts' of referrals combined with data of confirmed cases to show the proportion of all referrals that were confirmed as having a 'true allergy'. Only 1 in 5 patients (12-23\%) were diagnosed as having an allergy, with the majority of other referrals consisting of patients with idiopathic urticaria, food intolerance or non-specific symptomatology.

\section{Age and gender of patients}

The mean age of patients at referral was 35 (median 33). There were considerably more females than males (336 M (35\%), 625F (65\%)). There was no difference in mean age between males and females. Excluding 96 children, the mean age was 36 for women and 39 for men.

\section{Diagnosis rate by year and area}

The number referred and diagnosed with allergy each month ranged from 0 to 21 . Initially (1998-2001) referrals were predominantly from Plymouth postcodes but the percentage coming from other postcode areas increased to $40 \%$ in 2002-2005 and just under half in 2006-2009 (Additional file 1, Table A1).

\section{Referring GPs}

The 961 patients with diagnosed allergy were referred by a total of 672 different GPs. Most GPs (509, 76\%) referred only one patient. The most patients referred by any one GP was 11 . The 672 GPs came from 190 practices with the maximum referred from one practice being 39. Although this may reflect the presence of one or two very large practices, the variations between practices were considerable especially in Truro and Exeter

\section{Table 1 Referrals to the Peninsula Allergy Service and} the number of confirmed cases

\begin{tabular}{cccc}
\hline Year & Referrals & Confirmed & Percentage of referrals \\
\hline 1998 & 287 & 6 & Part year \\
1999 & 335 & 73 & 22 \\
2000 & 459 & 107 & 23 \\
2001 & 414 & 92 & 22 \\
2002 & 477 & 75 & 16 \\
2003 & 438 & 71 & 16 \\
2004 & 415 & 48 & 12 \\
2005 & 457 & 71 & 16 \\
2006 & 498 & 99 & 20 \\
2007 & 613 & 98 & 16 \\
2008 & 598 & 107 & 18 \\
2009 & 787 & 114 & Part year \\
\hline TOTAL & 5778 & 961 & $18^{*}$ \\
\hline
\end{tabular}

* the number of referrals was only available for full years so percentages of confirmed cases is only shown for ten full years and the overall percentage for those ten year. 
postcodes. Of the 28 practices with Truro postcodes one practice referred 27 people while the next most frequent referred only five. Of 44 practices with Exeter postcodes one practice referred 25 with the next most frequent referring only seven.

\section{Types of allergy}

Figures 1 and 2 show that 410/961 (43\%) had one or more food allergies and 689/961 (72\%) had one or more non-food allergies; 15\% (142) had both food and nonfood allergy. Nuts, fruit, and seafood (including fish and

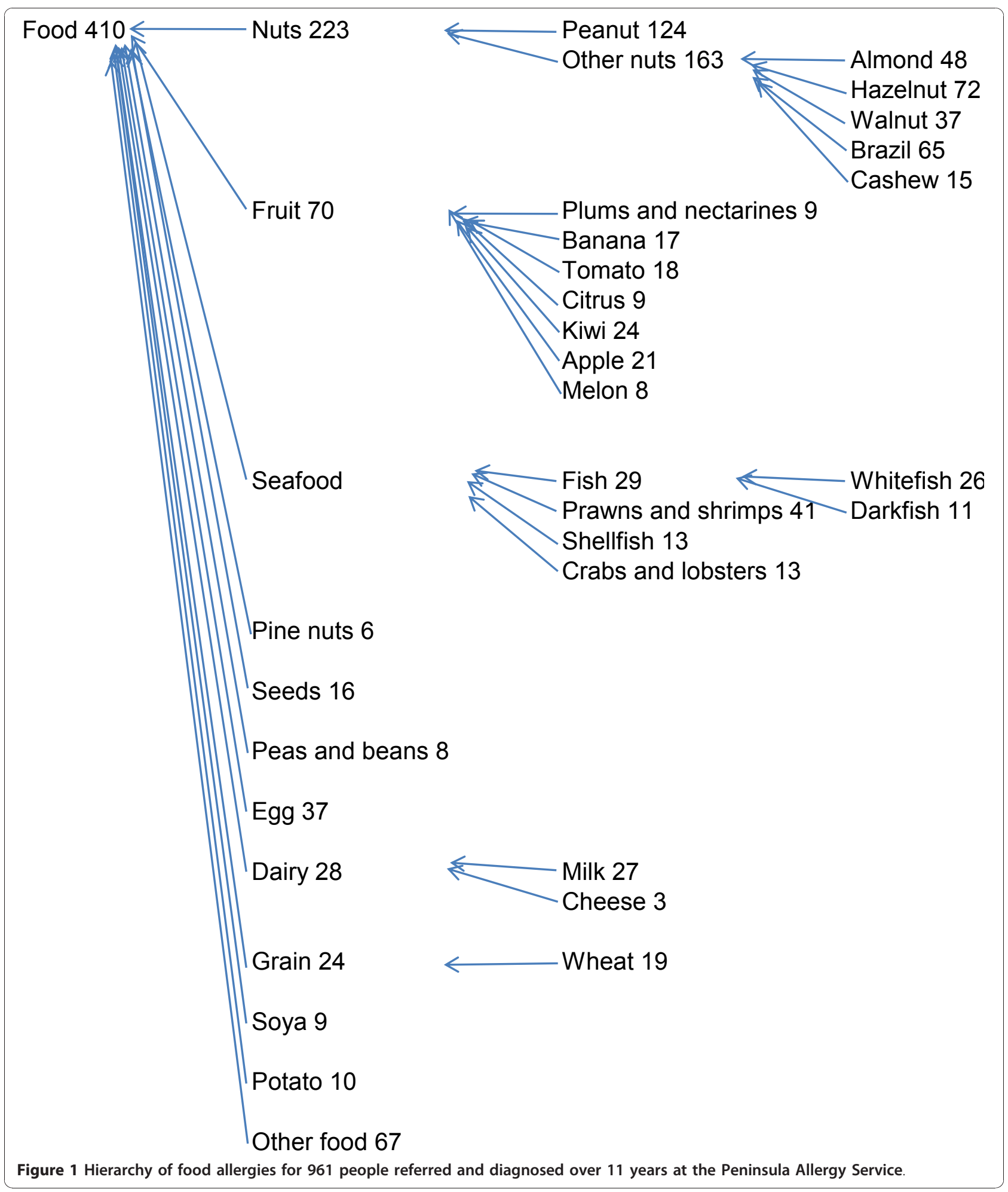




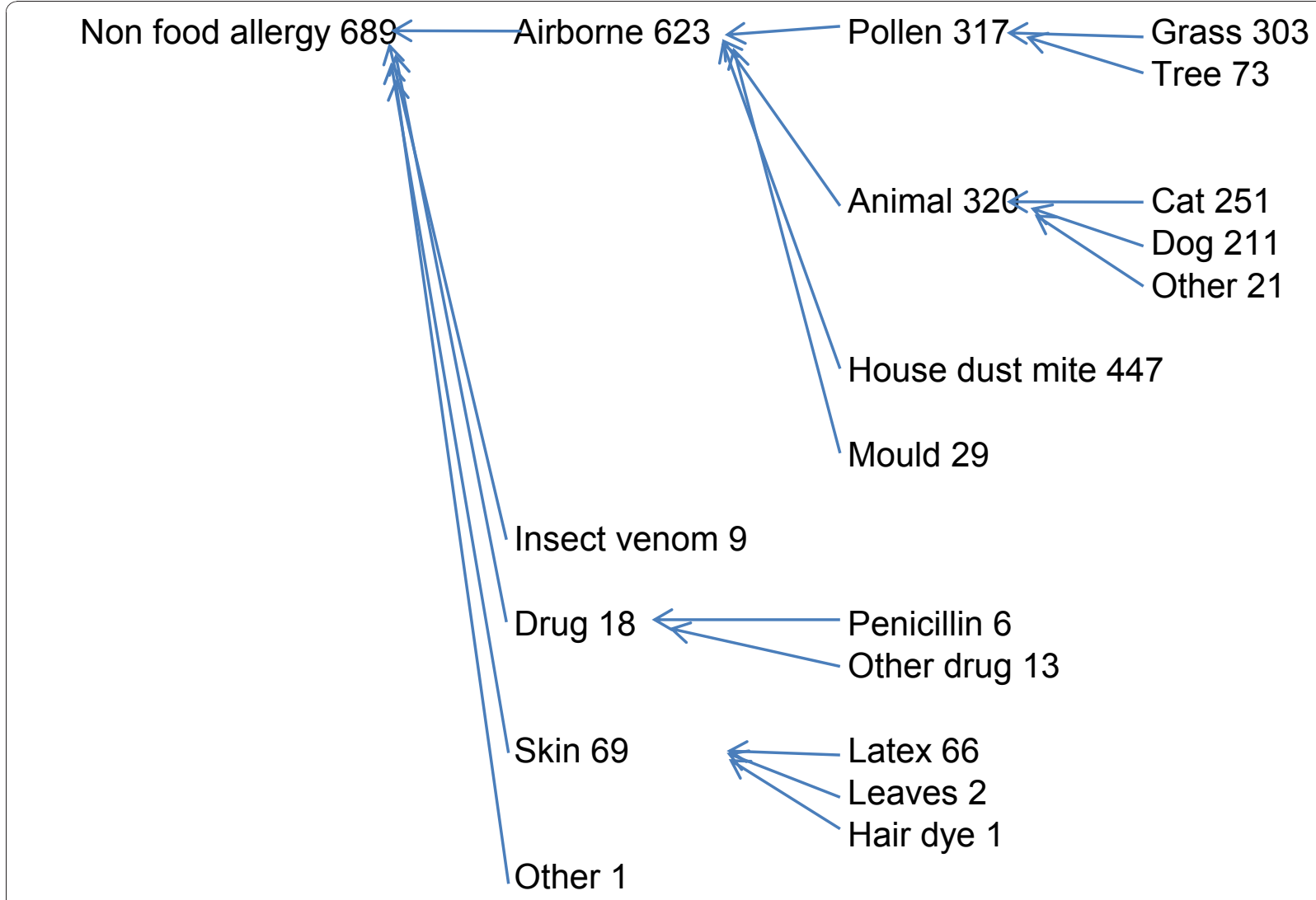

Figure 2 Hierarchy of non-food allergies for 961 people referred and diagnosed over 11 years at the Peninsula Allergy Service.

crustaceans), were the most frequent food allergies. Of the non food allergies, airborne allergies were the most frequent 623/689 and of these house dust mite, pollen, and animal hair all occurred frequently. The gender difference (more females than males) was greater for non food allergies (466F to $223 \mathrm{M} / 689$ ) than for food allergies (260F to $150 \mathrm{M} / 410)$.

\section{Co-occurrence of allergies}

We examined the co-occurrence of allergies, and used knowledge of cross-reactivity together with other allergen characteristics to aggregate and create 'allergy hierarchies' (Figures 1 and 2). For example, peanut, almond, hazel nut, walnut, brazil nut, cashew nut allergies cooccurred frequently. Pine nuts did not co-occur with these other nuts and but more often with seed allergies, but we have left them as separate items in most analyses. There was co-occurrence of white fish and dark fish allergies, and between (white and dark) fish and shellfish, and between fish and prawn-shrimp. Although fish did not co-occur so frequently with crab-lobster, as crab-lobster co-occurred with prawn-shrimp, we aggregated all into 'seafood'. In some cases, numbers were small and we grouped using common 'English language' categories, so only six people had penicillin allergies of which one was also allergic to 'other drugs' (erythromycin) but we nevertheless grouped as 'drugs'.

There were very high rates of co-occurrence of pollen, house dust mite, and animal hair allergies, so these were grouped as 'airborne' allergies. Table 2 shows the chances of being allergic to pollen, house dust mite, or animal hair given the known allergy to one of these three. For example, of those allergic to house dust mite, $53 \%$ were also allergic to animal hair and $46 \%$ to pollen. Of those allergic to pollen, $65 \%$ were allergic to house dust mite and $50 \%$ to animal hair.

\section{Other co-occurring allergies}

There were other co-occurring food allergies that were not aggregated on the basis of common English language

Table 2 Given known allergy to first allergen, the proportion who are allergic to second allergen

\begin{tabular}{|c|c|c|c|c|c|}
\hline & & \multicolumn{3}{|c|}{ Second Allergen } & \multirow[b]{2}{*}{ N } \\
\hline & & House dust & Animal & Pollen & \\
\hline \multirow[t]{3}{*}{ First Allergen } & House dust & & $53 \%$ & $46 \%$ & 447 \\
\hline & Animal & $74 \%$ & & $49 \%$ & 320 \\
\hline & Pollen & $65 \%$ & $50 \%$ & & 317 \\
\hline
\end{tabular}


aggregate terms but are interesting to note as possible cross-reactivity or co-occurrence for other reasons. These are shown in Table 3 . Of the 28 people allergic to dairy products, 13 were also allergic to egg, and seemed to have slightly more chance of allergy to other foods. Of 66 people allergic to latex 15 were also allergic to fruit. As previous authors had found cross-reactivity between latex and food allergies we also explored this further. Six out of 17 people allergic to banana and 5 out of 24 allergic to kiwi were also allergic to latex. There did not appear any association with other types of fruit or other foods.

\section{Number of allergies and unusual cases}

Most patients (60\%) had more than one allergy (median two) recorded. One patient had 10 items, one 11 items, and one 22 items (House dust mite, aspergillus, milk, wheat, egg, honey bee, grass pollen, peanuts, mixed fish, latex, tomatoes, raisins, rapeseed, lemon, grape, spices, carrots, asparagus, orange, pork, chicken and potato). Some of the rarer allergies included seminal fluid, celery, various medications (including porcine and human recombinant insulin, Hydroxocobalamin, and Fluoxetine), goat, yoghurt, and Pudu.

\section{Changes over time}

Although the number of patients referred and diagnosed each year has increased, this seems to be due to an increase in all allergies and not any particular allergy. (Additional file 1, Table A2 and Additional file 1, Figure A1).

\section{Age-gender differences in allergies}

People referred with food allergies were on average 5 years younger than the other referrals (37 Vs 32; $\mathrm{t}=5.1 ; \mathrm{p}=$ 0.017). Amongst the 410 with food allergy, those allergic to seafood were older (39 Vs 30; $\mathrm{t}=-4.4 ; \mathrm{p}<0.001)$, those allergic to nuts were much younger ( $26 \mathrm{Vs} 38$; $\mathrm{t}=8.7$;

Table 3 Co-occurring food allergies amongst 961 patients, showing most frequent food groups and the observed/expected numbers of patients with each allergy from $2 \times 2$ cross-tabulations

\begin{tabular}{llllllll}
\hline & nuts & sea & dairy & fruit & egg & grain & latex \\
\hline nuts & $\mathrm{N}=223$ & & & & & & \\
seafood & $10 / 16.5$ & $\mathrm{~N}=71$ & & & & & \\
dairy & $8 / 6.5$ & $6 / 2.1$ & $\mathrm{~N}=28$ & & & & \\
fruit & $22 / 16.2$ & $6 / 5.2$ & $7 / 2.0$ & $\mathrm{~N}=70$ & & & \\
egg & $15 / 8.6$ & $6 / 2.7$ & $13 / 1.1$ & $6 / 2.7$ & $\mathrm{~N}=37$ & & \\
grain & $6 / 5.6$ & $2 / 1.8$ & $3 / 0.7$ & $3 / 1.7$ & $4 / 0.9$ & $\mathrm{~N}=24$ & \\
latex & $7 / 15.3$ & $5 / 4.9$ & $6 / 1.9$ & $\mathbf{1 5 / 4 . 8}$ & $5 / 2.5$ & $3 / 1.6$ & $\mathrm{~N}=66$
\end{tabular}

The two bold cells (egg-dairy) and (latex-fruit) show where there is more cooccurrence than you would expect by chance (based on Fisher exact test and $\mathrm{p}<0.0024)$. $\mathrm{p}<0.001)$, those to allergic to egg were younger $(25 \mathrm{Vs} 32 ; \mathrm{t}$ $=2.7 ; \mathrm{p}=0.008$ ), but there was no age difference for fruit, dairy, or grain. The children under 16 were much more likely to have nut allergy $\left(45 \%\right.$ Vs $21 \%, \chi^{2}=28$, p < 0.001$)$ than adults. The only gender difference was for fruit: females were more likely to have fruit allergy (20 Vs 11\%; $\left.\chi^{2}=5.5 ; \mathrm{p}=0.019\right)$.

\section{Deprivation categories}

There was no significant difference in the deprivation scores of the 961 compared to all postcodes for Devon and Cornwall (Additional file 1, Table A3). Analysis of individual allergy types did not show any significant differences by deprivation.

\section{Geographic distribution of allergies}

Analysis of the 11- year rates by postcode district showed that there is evidence for a non-homogenous spatial distribution. This was also true if you looked at the subgroups of airborne allergies, pollen allergies, food allergies, and nut allergies. There was no clear evidence of spatial structuring for seafood or fruit, though in both cases the number of cases was small $(n=71$ and $70)$. However, latex allergies, also with a small sample (n $=66$ ), did have evidence of spatial structuring. Figure 3 shows crude and smoothed rates for airborne and food allergies. There appears to be a clear referral effect, i.e. some form of clustering around the referral hospital. However, the geographical distribution appears to vary between allergies, so for example, airborne (particularly pollen allergies) seem to cluster more to the north of Plymouth, whereas food allergies (particularly nut allergies) cluster more in the South Hams (to the South East of Derriford Hospital). Additional File shows other maps of Pollen $(n=317)$, Nuts $(n=223)$, Fruit $(n=70)$, Seafood $(n=71)$, Latex $(n=66))$. Seafood, although having small numbers and not statistically significant in the analysis above, seems to show a different distribution perhaps related to distance from the sea.

Figure 4 shows differences between particular allergies and a 'control' allergy to try to 'remove' the referral effect and explore possible environmental effects. We can see that comparing pollen allergy with food allergy we see more pollen allergies in the North Dartmoor and Exmoor areas. Comparing seafood with airborne, we see more seafood allergies in the far south west of Cornwall and in the Padstow area.

\section{Discussion}

It is difficult to compare the 11 year incidence rate of confirmed cases referred to this regional allergy service with previous research. Given the clinical confirmation of their allergies our population would have very few, if any, 'false positives'. However, given the variability of 


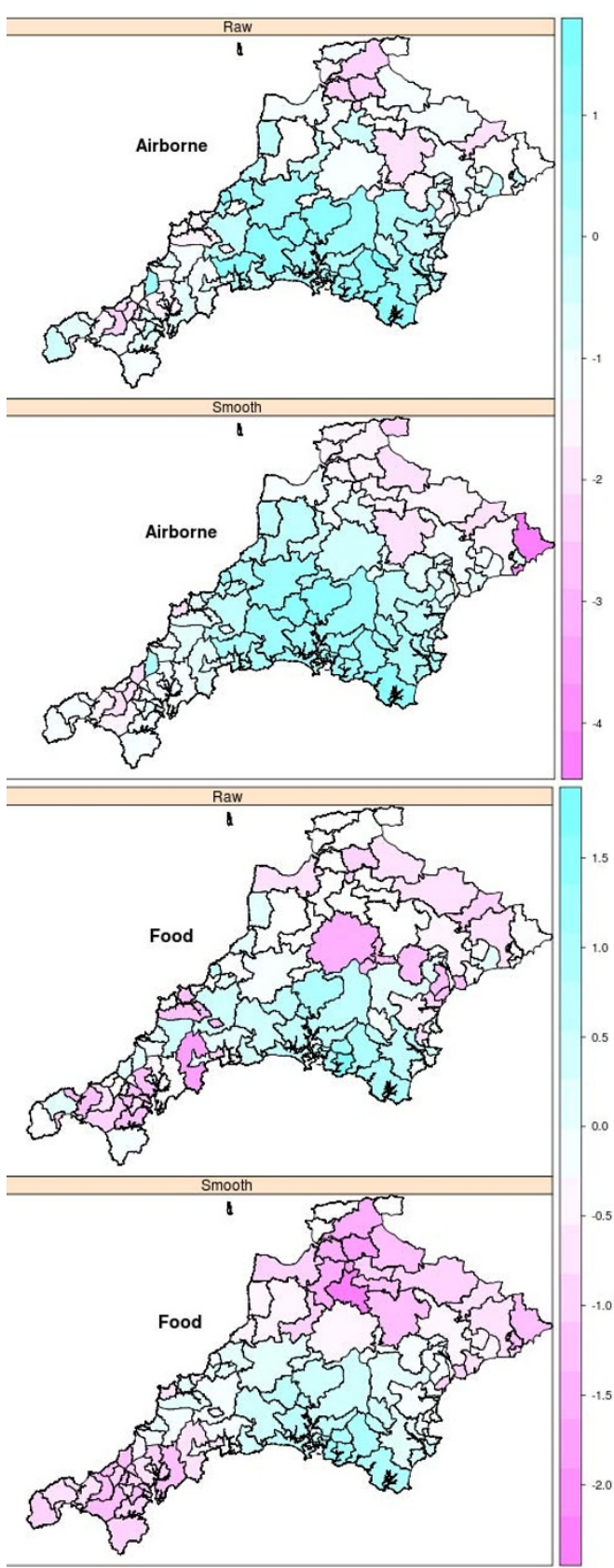

Figure 3 Postcode district maps showing Log of Standardised Morbidity Ratios for Allergies (as referred to Derriford Hospital), crude rates and smoothed rates: Airborne $(n=623)$, Food $(n=410)$.

referral by GPs, our incidence rate at a regional service would grossly underestimate the true population prevalence. On the other hand, many publications are population self-report 'allergies' $[8,9,11,13]$ many of which are likely to be due to intolerance or other conditions rather than allergies. Our cases were not self-report. Although both patients and GPs may have initially thought they 'had
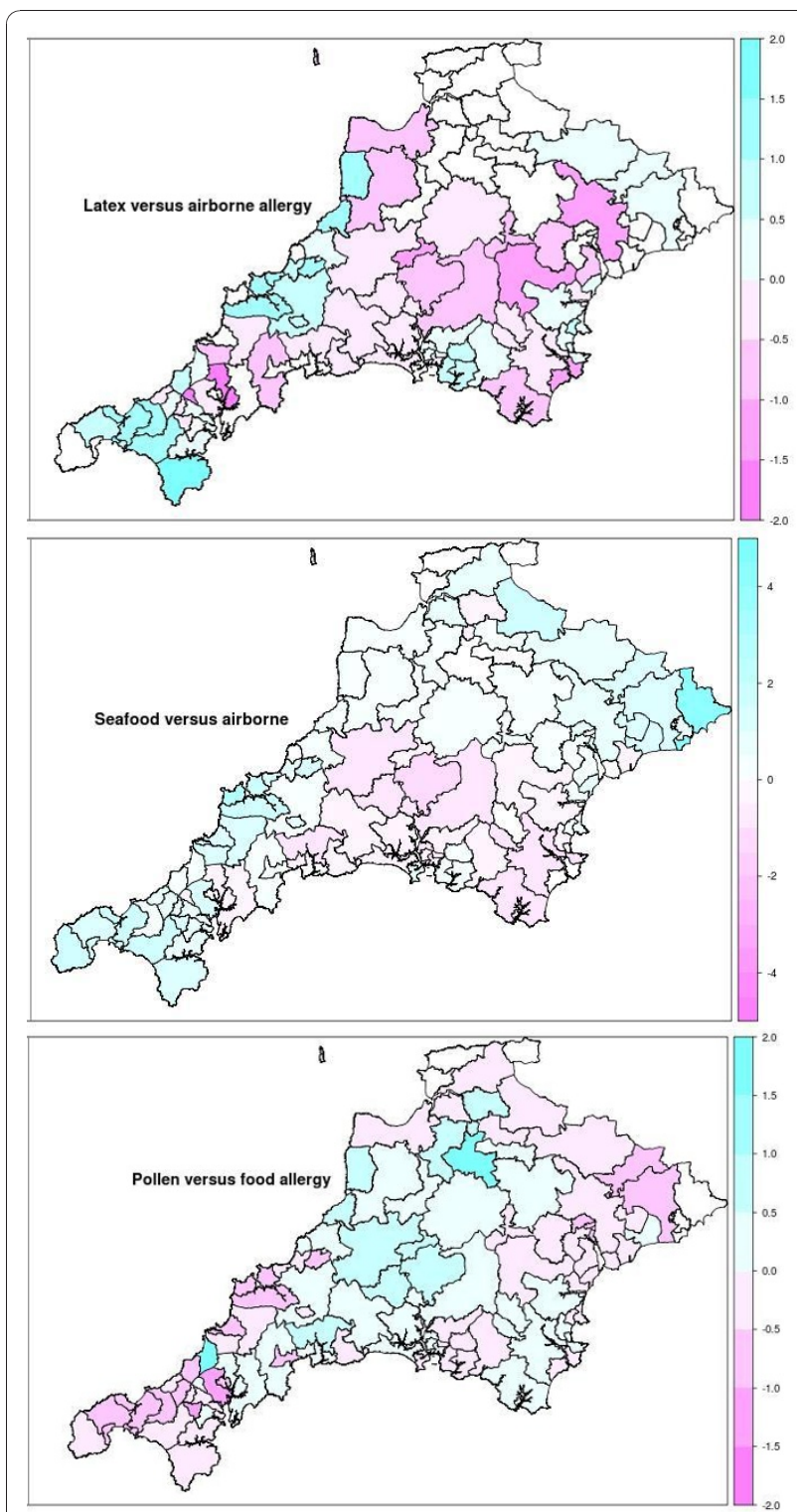

Figure 4 Postcode district maps showing Log of Standardised Morbidity Ratios for Allergies (as referred to Derriford Hospital), comparison of Pollen versus Food, Latex versus Airborne, Seafood versus Airborne.

an allergy', resulting in the referral to PAS, at best, only $23 \%$ of any one year's referrals were found to be allergy. There may be misconceptions about allergy in the public [21]. From clinical experience, many individuals attribute a number of non-specific symptoms, particularly gastrointestinal, headaches, etc to allergies. In addition to this, certain symptoms such as urticaria or angioedema which are indeed associated with allergies, can also occur due to non-allergy causes, and may be 'idiopathic' [22,23].

GPs may come under pressure from the general public for referral and an expert opinion [24]. Based on 800 
new patients per year to the PAS, the cost to Primary Care Trusts in Devon and Cornwall is approximately $£ 300,000$ (based on local cost data). Only one in five of these patients have an allergy. Previous unpublished audits suggest that at least a quarter of the referrals could be avoided saving $£ 75,000$ a year for the NHS and unnecessary travel and time off work for the patient.

There are few estimates of referred and confirmed allergy derived from clinic based studies. Asero et al [15] reported the types of allergy found in 25601 patients attending 17 allergy clinics throughout Italy, and Joral et al [6] reported the numbers of patients with food allergies in 3034 patients referred to two hospitals in the Basque country, but neither attempted to estimate population prevalence. A prevalence study in Madrid estimated that $11.6 \%$ of patients attending general practice had some allergy [25].

In a multicentre study in 1991-94, Woods et al found that $12 \%$ of adults aged $20-44$ from 15 countries, reported (on interview) adverse reactions to particular foodstuffs. This self-report figure varied considerably from $4.6 \%$ in Spain to $19.1 \%$ in Australia [26]. The true diagnosis of food allergy requires double blind, placebo-controlled food challenges (DBPCFC). In two DBPCFC population studies in the mid 1990 the prevalence of food allergy was estimated at $2.4 \%$ in the Netherlands [27] and 1.4-1.8\% in the UK [28]. In this audit of a clinic population, 410 cases of food allergy were referred to the PAS over 11 years from a population of 1.6 million which is $0.03 \%$ or a factor of 100 less than reported in these population studies. This suggests that very few people with allergy present to their GP and subsequently get referred.

Spatial structuring of rates of confirmed allergy referred to the PAS is quite clear. There is a clear proximity or referral effect, i.e. more referral from GPs closer to the hospital. We do not know what happens to people with allergies in more remote areas. In addition, assuming the proximity effect is consistent across different types of allergy, comparisons between allergies suggest environmental influences.

This audit therefore suggests that there are many people with allergy who could benefit from referral. The cost and impact of undiagnosed and untreated allergy can be considerable [4]. Based on 2009 data, if Exeter, Torquay, and Truro postcodes (i.e. those more remote from this regional centre) had the same levels of referral of true cases as Plymouth postcodes, then the number of true cases referred would increase from 150 to 222 per year. That there may be environmental influences on the prevalence of allergy is not new. For example, in Guipuzcoa in Spain, cow's milk and eggs were infrequent and fruit, seafood and vegetables were common allergies [6]. Joral et al attributed this to dietary habits. Two recent large studies appear to give contradictory evidence on air pollution and respiratory allergies. A large American study found evidence of adverse health for children living in areas with chronic exposure to higher levels of ozone and particulate matter with diameter less than 2.5 micrometres compared with children with lower exposure [29]. On the other hand a large UK study found no relationship between selfreported wheezing in the past year, asthma, eczema and hay fever and living within $150 \mathrm{~m}$ from a major road [30].

We are not aware of any previous spatial analysis based on referred and confirmed cases of allergy in a defined region such as the South West Peninsula. Pollen allergies seemed more prevalent in moor areas, food allergies (particularly nut allergies) in the South Hams, and skin allergies around Derriford Hospital. On small numbers, there was some indication of food from the sea in the far south west of Cornwall and in the Padstow area. These are based purely on an 'ecological association' and we have no evidence that these individuals had more contact with their allergens.

Cross-reactivity between allergens has been described before but usually for food types which are taxonomically similar. For example, Lack [1] summarises findings showing cross-reactivity between peanuts and legumes, peas, lentils and co-reactivity with tree nuts. Allergies in children are commonly directed to proteins from eggs, milk, wheat or soy [31]. Other recognised cross-reactivity syndromes include the latex fruit syndrome (cross reactivity between latex and avocados, bananas, kiwi, etc) [32] and the birch-fruit syndrome (cross reactivity between Birch pollen and a number of fruits such as apple, peach, plum and hazelnuts) [33]. In France in 2001, Kanny found that food allergy was four times more likely in people with allergy to latex [11]. We found no such association with food (perhaps reflecting different levels of fruit consumption in France and SW England), but there were cooccurrence of latex with banana and kiwi allergies. Our data showed clear relationships between egg and dairy allergies and some suggestion (based on small numbers) of other co-occurrence that would be worthy of further investigation.

Our audit has limitations from combining different data sources. Our estimates of true positive/all cases are based on the numerator from letters from the PAS to GPs about confirmed cases while the denominator comes from hospital statistics of referral. This means we cannot separate the true positive/all cases between inhalant and food allergy as we do not have separate denominators. Our spatial analysis uses population figures from the 2001 census and it is possible that some areas may have had population migration affecting referral rates.

\section{Conclusions}

This 11-year audit of a regional service serving a welldefined geographical area suggests that there is both 
unmet need and inappropriate referral. GPs may benefit from education and ongoing decision support. Public education on the nature of allergy, and intolerance and how these may be treated should also be considered. It also suggests further research into what happens to patients with allergy where there has been low use of tertiary services. Finally, it suggests further research into co-occurrence, cross-reactivity, and spatial distribution of allergy.

\section{Additional material}

Additional file 1: Table A1. Numbers referred and diagnosed with allergy by year of clinic and 2 character postcode of address, showing also the total population from 2001 census and 11 year rate per 100,000 population. Table A2. Number of diagnoses for food and non food allergies showing most frequently occurring sub groups, by year (partial years in 1998 and 2009). Table A3. 'Deprivation deciles of the 961 people in this study, postcodes in Devon and Cornwall, and in England and Wales. Figure A1. Number of confirmed cases referred by year and type of allergy. Figures A2. Log of Standardised Morbidity Ratios for Allergies (as referred to Derriford Hospital), crude rates and smoothed rates: Pollen $(n=317)$, Nuts $(n=223)$, Fruit $(n=70)$, Seafood $(n=71)$, Latex $(n=66)$.

Additional file 2: Further details of the spatial analysis

\section{List of Abbreviations}

GP: General Practitioner; IgE: Immunoglobulin E (see e.g. http://en.wikipedia. org/wiki/Immunoglobulin_E); NHS: National Health Service; PAS: Peninsula Allergy Service.

\section{Acknowledgements}

We would like to thank Dr Claire Bethune, who was responsible for part of the patient case load. We thank Dr Maged Kamel Boulos and Dr Mar Soler Lopez, who read and commented on the manuscript. We thank Tim Absalom for initial help with Geographic Information Systems and the downloading of data from EDINA. We thank Schering-Plough who funded the data extraction and Mohinder Chakkar who extracted the data from GP letters.

\section{Author details}

'Faculty of Health, University of Plymouth, 3 Portland Villas, Plymouth PL4 8AA, UK. ${ }^{2}$ Department of Statistics, University of Plymouth, Kirkby Place, Plymouth PL4 8AA, UK. ${ }^{3}$ Department of Clinical Immunology \& Allergy, Derriford Hospital, Plymouth PL6 8DH, UK.

\section{Authors' contributions}

ERK and RBJ had the idea for the study. RBJ managed the project, carried out initial data cleaning and analysis including initial spatial analysis, and wrote the paper. PH carried out the definitive spatial analysis and edited the paper. ERK was lead clinician in the PAS and was responsible for the clinical data used, with RBJ oversaw the data entry and cleaning, added clinical context to the paper and advised RBJ on aspects of analysis, worked with RBJ on the literature review, and edited the paper. All authors read and approved the final manuscript.

\section{Competing interests}

The authors declare that they have no competing interests.

Received: 24 June 2010 Accepted: 29 December 2010 Published: 29 December 2010

\section{References}

1. Lack G: Clinical practice. Food allergy. New England Journal of Medicine 2008, 359(12):1252-1260
2. Fox K: Finished admissions episodes for primary diagnosis of anaphylaxis in England in 2004-2009 by age group and diagnosis, based on Hospital Episode Statistics. Ad hoc report prepared by NHS Information Centre for Health and Social Care. 2010.

3. Moneret-Vautrin DA, Morisset M, Flabbee J, Beaudouin E, Kanny G Epidemiology of life-threatening and lethal anaphylaxis: a review. Allergy 2005, 60(4):443-451.

4. Department of Health Allergy Services Review Team: A review of services for allergy. The epidemiology, demand for and provision of treatment and effectiveness of clinical interventions. 2006, 102[http://www.dh.gov. uk/en/Publicationsandstatistics/Publications/PublicationsPolicyAndGuidance/ DH_4137365].

5. Royal College of Physicians: Allergy services: still not meeting the unmet need. London: Royal College of Physicians and Royal College of Pathologists; 2010.

6. Joral A, Villas F, Garmendia J, Villareal O: Adverse reactions to food in adults. J Invest Allergol Clin Immunol 1995, 5(1):47-49.

7. Wuthrich $B$, Schindler $C$, Leuenberger $P$, Ackermannliebrich $U$, Alean $P$, Blaser K, Bolognini G, Bongard JP, Brandli O, Braun P, et al: Prevalence of atopy and pollinosis in the adult-population of Switzerland (SAPALDIA study). Int Arch Allergy Immunol 1995, 106(2):149-156.

8. Keiding L: Astma, Allergi og Anden Overfølsomhed i Danmark - Og Udviklingen 1987-1991. (Asthma, Allergy and Other Hypersensitivities in Denmark, 1987-1994.). Copenhagen, Denmark: Dansk Institut for Klinisk Epidemiologi; 1997.

9. Emmett SE, Angus FJ, Fry JS, Lee PN: Perceived prevalence of peanut allergy in Great Britain and its association with other atopic conditions and with peanut allergy in other household members. Allergy 1999, 54(4):380-385.

10. Crespo JF, Rodriguez J: Food allergy in adulthood. Allergy 2003, 58(2):98-113.

11. Kanny G, Moneret-Vautrin DA, Flabbee J, Beaudouin E, Morisset M, Thevenin F: Population study of food allergy in France. Journal of Allergy and Clinical Immunology 2001, 108(1):133-140.

12. Zuberbier T, Edenharter G, Worm M, Ehlers I, Reimann S, Hantke T, Roehr CC, Bergmann KE, Niggemann B: Prevalence of adverse reactions to food in Germany - a population study. Allergy 2004, 59(3):338-345.

13. Osterballe M, Hansen TK, Mortz CG, Host A, Bindslev-Jensen C: The prevalence of food hypersensitivity in an unselected population of children and adults. Pediatric Allergy and Immunology 2005, 16(7):567-573.

14. Jarvis D, Luczynska C, Chinn S, Potts J, Sunyer J, Janson C, Svanes C, Kunzli N, Leynaert B, Heinrich J, et al: Change in prevalence of lgE sensitization and mean total lgE with age and cohort. Journal of Allergy and Clinical Immunology 2005, 116(3):675-682.

15. Asero R, Antonicelli L, Arena A, Bommarito L, Caruso B, Crivellaro M, Carli M, Torre E, Torre F, Heffler E, et al: EpidemAAITO: Features of food allergy in Italian adults attending allergy clinics: a multi-centre study. Clin Exp Allergy 2009, 39(4):547-555.

16. Madsen C: Prevalence of food allergy: an overview. Proc Nutr Soc 2005, 64(4):413-417.

17. Rona RJ, Keil T, Summers C, Gislason D, Zuidmeer L, Sodergren $E_{\text {, }}$ Sigurdardottir ST, Lindner T, Goldhahn K, Dahlstrom J, et al: The prevalence of food allergy: A meta-analysis. Journal of Allergy and Clinical Immunology 2007, 120(3):638-646.

18. Zuidmeer L, Goldhahn K, Rona RJ, Gislason D, Madsen C, Summers C, Sodergren E, Dahlstrom J, Lindner T, Sigurdardottir ST, et al: The prevalence of plant food allergies: a systematic review. The Journal of Allergy And Clinical Immunology 2008, 121(5):1210-1218.e1214.

19. Potthoff $R$, Whittinghill M: Testing for Homogeniety: The Poisson Distribution. Biometrika 1996, 53:183-190.

20. Moran PAP: The interpretation of statistical maps. Journal of the Royal Statistical Society Series B 1948, 10:243-251.

21. Gupta RS, Kim JS, Springston EE, Pongracic JA, Wang XB, Holl J: Development of the Chicago Food Allergy Research Surveys: assessing knowledge, attitudes, and beliefs of parents, physicians, and the general public. BMC Health Serv Res 2009, 9:9.

22. Chung MC, Symons C, Gilliam J, Kaminski ER: Stress, psychiatric comorbidity and coping in patients with chronic idiopathic urticaria. Psychology \& Health 25(4):477-490.

23. Chung MC, Symons C, Gilliam J, Kaminski ER: The relationship between posttraumatic stress disorder, psychiatric comorbidity, and personality 
traits among patients with chronic idiopathic urticaria. Comprehensive Psychiatry 51(1):55-63.

24. Little P, Dorward M, Warner G, Stephens K, Senior J, Moore M: Importance of patient pressure and perceived pressure and perceived medical need for investigations, referral, and prescribing in primary care: nested observational study. BMJ 2004, 328(7437):444

25. Esteban-Vasallo MD, Dominguez-Berjon MF, Astray-Mochales J, GenovaMaleras R, Perez-Sania A, Sanchez-Perruca L, Aguilera-Guzman M, GonzalezSanz FJ: Epidemiological usefulness of population-based electronic clinical records in primary care: estimation of the prevalence of chronic diseases. Fam Pr 2009, 26(6):445-454.

26. Woods RK, Abramson M, Bailey M, Walters EH: International prevalences of reported food allergies and intolerances. Comparisons arising from the European Community Respiratory Health Survey (ECRHS) 1991-1994. European Journal Of Clinical Nutrition 2001, 55(4):298-304.

27. Jansen JJ, Kardinaal AF, Huijbers G, Vlieg-Boerstra BJ, Martens BP, Ockhuizen T: Prevalence of food allergy and intolerance in the adult Dutch population. The Journal Of Allergy And Clinical Immunology 1994, 93(2):446-456.

28. Young E, Stoneham MD, Petruckevitch A, Barton J, Rona R: A population study of food intolerance. Lancet 1994, 343(8906):1127-1130.

29. Parker JD, Akinbami LJ, Woodruff TJ: Air Pollution and Childhood Respiratory Allergies in the United States. Environ Health Perspect 2009, 117(1):140-147.

30. Pujades-Rodriguez M, Lewis S, McKeever T, Britton J, Venn A: Effect of living close to a main road on asthma, allergy, lung function and chronic obstructive pulmonary disease. Occup Environ Med 2009, 66(10):679-684.

31. Kulig M, Bergmann R, Klettke U, Wahn V, Tacke U, Wahn U: Natural course of sensitization to food and inhalant allergens during the first 6 years of life. The Journal Of Allergy And Clinical Immunology 1999, 103(6):1173-1179.

32. M'Raihi L, Charpin D, Pons A, Bongrand P, Vervloet D: Cross-reactivity between latex and banana. The Journal Of Allergy And Clinical Immunology 1991, 87(1 Pt 1):129-130.

33. Anderson $\mathrm{K}$, Lowenstein $\mathrm{H}$ : An investigation of the possible immunological relationship between allergen extracts from birch pollen, hazelnut, potato and apple. Contact Dermatitis 1970, 4:73-78.

\section{Pre-publication history}

The pre-publication history for this paper can be accessed here:

http://www.biomedcentral.com/1471-2458/10/790/prepub

doi:10.1186/1471-2458-10-790

Cite this article as: Jones et al:: Referrals to a regional allergy clinic - an eleven year audit. BMC Public Health 2010 10:790.

\section{Submit your next manuscript to BioMed Central and take full advantage of:}

- Convenient online submission

- Thorough peer review

- No space constraints or color figure charges

- Immediate publication on acceptance

- Inclusion in PubMed, CAS, Scopus and Google Scholar

- Research which is freely available for redistribution

Submit your manuscript at www.biomedcentral.com/submit
Biomed Central 